\title{
Las células troncales pluripotenciales en la terapia celular
}

\section{Pluripotent stem cells on cell therapy}

\section{J.A. Gámez Escalona ${ }^{1}$, N. López Moratalla ${ }^{2}$}

\section{RESUMEN}

Las células con pluripotencialidad inducida (iPS) son un nuevo tipo de célula troncal derivada de células somáticas humanas, mediante reprogramación con factores de transcripción. Estas células iPS tienen características de las células troncales embrionarias, como la capacidad de convertirse en todos los tipos de células diferenciadas del organismo. A corto plazo, las células de pacientes reprogramadas están siendo útiles para crear modelos celulares de enfermedades, en las que estudiar los procesos patológicos y probar fármacos. A pesar de algunas críticas, se ha ido acumulando evidencia en los trabajos preclínicos, sobre la efectividad de la terapia celular con los clones de iPS apropiadamente seleccionados. La generación de células iPS ha propiciado el desarrollo de otras técnicas,como por ejemplo, la transdiferenciación por la que se convierte directamente in vivo fibroblastos cardiacos en miocitos. Este tipo celular pluripotencial es de un gran valor en la investigación biomedicina y abre nuevas posibilidades a la terapia celular.

Palabras claves. Células troncales. Pluripotencialidad inducida (iPS). Modelos celulares de enfermedad. Reprogramación. Terapia celular.

\begin{abstract}
Induced pluripotent stem (iPS) cells are a novel stem cell population derived from human somatic cells through reprogramming using a set of transcription factors. These iPS cells were shown to share the characteristics of embryonic stem cells, including the ability to give rise to differentiated cells of every tissue type of the body. In the shorter term, iPS cells will be useful for creating patient-identical disease model cells in which the pathological process can be studied and drugs can be tested. Despite critical attitudes, accumulating preclinical evidence supports the effectiveness of iPSCbased cell therapy on the selection of appropriate iPSC clones. The production of iPS cells has also spurred the development of other techniques, for example, transdifferentiation by researchers can now convert heart fibroblasts directly in vivo into myocytes by similar methods. This pluripotent cells is indeed of great value in medical research and it is opening new possibilities in cell therapy.
\end{abstract}

Key words. Stem cells. Induced pluripotent stem (iPS) cells. Disease model cells. Reprogramming. Cell therapy
1. Universidad de Monteávila. Caracas

2. Universidad de Navarra. Pamplona

Recepción: 4 de septiembre de 2013

Aceptación provisional: 2 de octubre de 2013

Aceptación definitiva: 7 de octubre de 2013

\author{
Correspondencia: \\ JA Gámez Escalona \\ Universidad de Monteávila. \\ Caracas \\ jgamez@uma.edu.ve
}




\section{LOS INICIOS DE LA TERAPIA CELULAR EN 2006}

Las células troncales de adulto, presentes en todos los órganos, tejidos y sistemas, constituyen una reserva orgánica cuya función natural es la regeneración de las células diferenciadas destruidas por enfermedad o accidente. La Medicina Regenerativa trata de encontrar el modo de potenciar in vitro su función natural y, en el futuro, conseguir ese objetivo sin manipularlas fuera del organismo.

A medida que aumenta el grado de diferenciación de las células troncales -pluripotenciales, multipotenciales o progenitoras disminuye la capacidad proliferativa característica de las células indiferenciadas-. Resultaron, por ello, las células de las reservas del organismo muy escasas para investigar sus propiedades, en vistas a su uso terapéutico. Por esto, desde hace cerca de 10 años se busca "rejuvenecer" células de adulto, llevándolas en dirección contraria a la del desarrollo embrionario, hasta alcanzar el estado pluripotencial ${ }^{1}$, en el que no están totalmente comprometidas hacia una línea celular concreta.

El interés por el fenómeno de la pluripotencialidad proviene del aislamiento y la derivación de las células troncales de origen embrionario ${ }^{2}$. Sin embargo, el avance de los trabajos para conocer los mecanismos de este fenómeno vino con la obtención de células con pluripotencialidad inducida -iPS, por sus siglas en ingles Induced Pluripotent Stem- de ratón en $2006^{3}$, y en humanas en 2007, por el mismo equipo de Yamanaka ${ }^{4}$ y el de Thomson ${ }^{5}$. También en 2007 se publicó la primera prueba de uso terapéutico de iPS, en ratones a los que se les había inducido una anemia ${ }^{6}$.

Superados los inconvenientes de la tecnología usada -transferencia de genes mediante un vector viral ${ }^{7}$ siendo uno de ellos el oncogenMyc ${ }^{8}$-, que comprometía la seguridad en caso de aplicaciones clínicas ${ }^{9}$, tiene lugar en menos de 5 años un despliegue de conocimientos sin precedentes en la biología de las células troncales ${ }^{10}$.

Se logran iPS de diversos tejidos incluso de donantes enfermos ${ }^{11}$-por ejemplo de pacientes con atrofia muscular ${ }^{12}$ - lo que aporta un material de enorme valor para conocer los mecanismos moleculares de diversas enfermedades y diseñar y probar terapias y fármacos con modelos celulares humanos $^{13}$. La necesidad de modelos humanos es evidente; adipocitos ${ }^{14}$ y cardiomiocitos ${ }^{15}$ han sido los primeros modelos conseguidos.

En esos años, el equipo de Melton inicia la proeza de conseguir rejuvenecer o diferenciar las células in vivo ${ }^{16}$; una estrategia diferente con los mismos objetivos: conseguir una mayor cantidad de células troncales de la reserva natural para terapias regenerativas. Células troncales como los fibroblastos se han podido convertir in vitro a células somáticas tales como células neurales $^{17}$, hepatocitos ${ }^{18}$, miocitos cardiacos ${ }^{19}, \mathrm{y}$ células progenitoras hematopoyéticas ${ }^{20}$. Los conocimientos del proceso de desdiferenciación-rediferenciación a través de la reprogramación al estado pluripotencial ayudará, sin duda, a la reprogramación directa in situ, transdiferenciación, probablemente el mejor sistema para la Medicina Regenerativa.

\section{LA PLURIPOTENCIALIDAD CELULAR}

Tres líneas de investigación inspiraron el descubrimiento de la reprogramación hacia atrás con las $\mathrm{iPS}^{21}$ : la reprogramación celular por transferencia nuclear, iniciada por John Gurdon en 1962, que mostró la posibilidad de dar marcha atrás en el proceso de diferenciación. El descubrimiento de los factores de transcripción a partir de los experimentos de Schneuwly desde 1987, esenciales para conocer el mecanismo de la des-diferenciación, y los trabajos de aislamiento y cultivo de células troncales pluripotenciales de origen embrionario, que comenzaron con la primera obtención de las de ratón en 1981.

Los numerosos intentos de reprogramar hacia atrás el núcleo de una célula somática transfiriéndola a un oocito ${ }^{22}$, sugeríanla existencia de una combinación de factores en los óvulos y/o en las células embrionarias capaces de des-diferenciar una célula madura. En el momento en que el equipo de Yamanaka comienza su estudio se cono- 
cían unos 24 factores de la pluripotencia$\operatorname{lidad}^{23}$. En cinco años definen los factores necesarios para inducir la reprogramación ${ }^{24}$. El desarrollo de las iPS se presenta, por tanto, como un ensayo bioquímico de la pluripotencialidad. Las modificaciones cualitativas y cuantitativas sobre este ensayo experimental van revelando mecanismos bioquímicos y genéticos, hasta ahora ignorados. Citamos algunos avances:

- Una mayor comprensión de la Epigenética, paradigma esencial de la Biología Celular y del Desarrollo, al conocer la regulación de la represión/ expresión de los factores de transcripción que comprometen a linajes celulares específicos. Aunque se conocía $^{25}$ que algunas células quedan reprogramadas solo parcialmente por esta falta de regulación, se avanza en el conocimiento de los mecanismos de la plasticidad celular.

- Un mejor conocimiento de los RNA reguladores implicados en la optimización del proceso de inducción de la pluripotencialidad ${ }^{26}$, así como de las vías de señalización ${ }^{27}$.

- Es de interés, dada la similitud que existe entre los procesos de transcripción de las células troncales pluripotenciales y la transformación tumoral, averiguar cuáles son los genes clave que mantienen a las células protegidas de los elementos que pueden inducir su des-diferenciación. Posiblemente se descubran nuevos supresores de tumores ${ }^{28}$, que modulan la estabilidad de la célula diferenciada.

- Las iPS pueden aportar también nuevos conocimientos a los fundamentos moleculares de la generación de los tumores de células germinales ya que los tumores de células germinales tienen una batería de factores de transcripción similar al de las iPS ${ }^{29}$.

\section{LA INVESTIGACIÓN DE LA PLURIPOTENCIALIDAD INDUCIDA}

La obtención de las iPS es un proceso clonal y por eso las características de los clones obtenidos por diversos métodos y en diversos laboratorios difieren entre sí. Se hizo preciso establecer cuáles serían los clones que asegurarían la diferenciación total, lógicamente imprescindible para poder avanzar en su posible uso en Medicina Regenerativa. Se llevó a cabo un gran trabajo para purificar correctamente y evaluar la efectividad y seguridad los miles de clones y subclones de iPS existentes. Además, el proceso de inducción del estado pluripotencial en las células es muy poco eficaz, muy lento, y la reprogramación es parcial. Se han ofrecido varias explicaciones, lo que va dando lugar a conocer paulatinamente algo más de los mecanismos de la programación y reprogramación celular ${ }^{30}$, de gran valor biomédico ${ }^{31}$.

Un aspecto controvertido ha sido el estándar mediante el que se evalúa la pluripotencialidad $^{32}$, tanto en el caso de los estudios de este fenómeno como para las posibles aplicaciones terapéuticas. La experiencia acumulada con las células troncales procedentes de embriones hizo que muchos plantearan como exigencia que éstas fueran el control para evaluar las iPS; sin embargo, se ha podido demostrar que hay diferencias en la expresión génica entre ambos tipos de células pluripotenciales $^{33}$ en la metilación del ADN, clave en la regulación epigenética durante la maduración de las células pluripotenciales ${ }^{34}$. Por el contrario, otros laboratorios mostraron que muchos de los clones derivados de las embrionarias o de las iPS se superponen en la expresión génica ${ }^{35}$.

Otro aspecto importante de discusión ha sido la capacidad de las células iPSpara diferenciarse. Se planteó llevarlo a cabo también por comparación de las derivadas de éstas con las derivadas de las células procedentes de los embriones, que serían el control.

Un criterio clave para conocer la capacidad de diferenciación es la posibilidad de asociación espontánea como cuerpos embrioides; este tipo de estructuracióncelular permite una diferenciación regional en la que se pueden distinguir, mediante marcadores moleculares, células pertenecientes a las tres capas germinales; dicha capacidad la presentan también las iPS, como se 
puso de manifiesto en $2007^{36}$. Es más, el hecho de que en las iPS persistan marcadores de la línea de la célula somática de la que se originó ${ }^{37}$, permitió conocer que al menos algunos clones de iPS, alcanzaban la pluripotencialidaddes-diferenciándose hacia atrás, esto es, a un estado más inmaduro, pero sin llegar al estado embrionario.

La eficacia de la diferenciación ha resultado muy variable ${ }^{38}$, como era de esperar puesto que la célula iPS resultante es de por sí variable, lo cual se debe, como se indica más arriba, a que la inducción de la pluripotencialidad es un proceso clonal. Actualmente se persigue la identificación de un patrón de expresión genética y epigenética que defina la reprogramación total de ambos tipos de células pluripotenciales para disponer de una prueba objetiva para el análisis de las líneas celulares que se generen desde ellas ${ }^{39}$.

El marcado carácter ético con que el pionero de las iPS, Yamanaka, llevó a cabo sus trabajos le llevó a buscar estrategias que evitaran el uso como controles de las células procedentes de embriones. Por una parte, cuando el proceso de rediferenciación de células pluripotencialesde ratón puede ser extrapolable a células humanas, la comparación entre células embrionarias e iPS quedó resuelto con los marcadores de la diferenciación de las líneas celulares murinas. Así ocurrió con las células de la retina generadas a partir de $\mathrm{iPS}^{40}$. Por otra parte, realizó en colaboración con el equipo de Jaenisch, la trayectoria de cambio de marcadores durante el desarrollo embrionario murino mediante una original estrategia consistente en examinar las proteínas de membrana de las células presentes a lo largo del proceso espacio-temporal del desarrollo $^{41}$.

Algunos autores señalaron que estas células contienen defectos, como mutaciones somáticas ${ }^{42}$, variaciones del número de $\operatorname{copias}^{43}$, e inmunogenicidad ${ }^{44}$, entre otros. Sin embargo, y especialmente en las obtenidas de enfermos, las alteraciones parecen estar en la célula somática original, y por tanto son defectos de la célula original y no del proceso mismo de la reprogramación, como se publicó en $2011^{45}$, aspecto éste que es clave en la búsqueda de modelos celulares de enfermedad humana.

A 2013, el interés en generar iPS, en el que la pluripotencialidad se puede obtener por factores de transcripción-transducción desde células somáticas, se ha incrementado rápidamente ${ }^{46}$, ya que se prevé que abrirán una gran cantidad de oportunidades en la biomedicina. Los peligros de esta tecnología que acabamos de señalar relacionados con la seguridad de la terapia no tienen apoyo en los estudios preclínicos que muestran la eficacia. Los estudios iniciales requerirán trasplante de estas células en animales inmunodeficientes, con la subsiguiente observación a largo plazo.

\section{AVANCES EN LA APLICACIÓN TERAPÉTICA DE LAS CÉLULAS CON PLURIPOTENCIALIDAD INDUCIDA}

La reprogramación de células somáticas tanto in vitrocomo in vivo supone ya, de hecho, un avance para el estudio de diversas enfermedades.

A corto plazo las iPS suponen la posibilidad de disponer de modelos para la investigación que conduce al descubrimiento de drogas específicas, toxicología y farmacología predictiva, como recoge el artículo de Yamanaka, ya citado, de 2012 sobre el presente y futuro de estas células. A más largo plazo se prevé poder usarlas en sustitución de células dañadas.

La experimentación animal se viene realizando con éxito, lo que da expectativas a una cierto largo plazo. Los avances se centran en el tratamiento de la enfermedad Parkinson $^{47}$, la deficiencia de plaquetas ${ }^{48}$, la lesión de la médula espinal ${ }^{49}$ y la degeneración macular ${ }^{50}$. En Japón esta tecnología recibe un impulso clave con la aprobación del primer ensayo clínico mediante el uso de las iPS para el tratamiento de la degeneración macular ${ }^{51}$. En diciembre de 2012 se prueba con éxito la recuperación de la lesión de la medula espinal en marmotas con células troncales neurales derivadas de iPS humanas ${ }^{52}$.

Los modelos celulares para el estudio de enfermedades, tanto de los mecanismos 
de la enfermedad como de la investigación de nuevos potenciales tratamientos, avanzan con la enfermedad de Alzheimer ${ }^{53}$ y la esquizofrenia ${ }^{54}$. Otros modelos se dirigen a enfermedades genéticas, como el síndrome CINCA $^{55}$, infecciosas como la hepatitis $\mathrm{C}$ utilizando iPS infectadas con el virus ${ }^{56}$. Para algunas enfermedades hematológicas las iPS como la anemia de Falconi han mostrado no solo servir para establecer modelos celulares de estudio de la enfermedad, sino que además han proporcionado una posibilidad de tratamiento mediante la generación de líneas celulares libres de enfermedad. De esta forma se muestra que las iPS pueden tener también un gran potencial terapéutico ${ }^{57}$. En cada caso es necesario examinar qué parte del desarrollo in vivo puede ser recapitulado en el modelo celular de la enfermedad.

La infertilidad o la esterilidad causadas por la alteración o la ausencia de células germinales permanecen incurable en gran medida. Para el estudio de los mecanismos moleculares que la originan, y el desarrollo de fármacos para su posible tratamiento, se requieren células germinales humanas. En 2012 un equipo liderado por Yamanaka, ha conseguido presentar un modelo de enfermedad consistente en la producción de células germinales por inducción de pluripotencialidada partir de células somáticas del paciente ${ }^{58}$. De nuevo el planteamiento ético del pionero Yamanaka encauza el posible uso de las iPS para manipulación de la reproducción humana hacia una rigurosa investigación de la infertilidad ${ }^{59}$.

También en 2012 consiguen una nueva estrategia de reprogramar fibroblastos cardiacos in vivo mediante terapia genética ${ }^{60}$, de gran interés. Como es conocido, la enfermedad cardíaca es la principal causa de morbilidad y mortalidad en todo el mundo y los enfoques terapéuticos actuales para la insuficiencia cardiaca son limitados debido a que los cardiomiocitos postnatales tienen poca capacidad regenerativa. Se había tratado de incorporar por ingeniería genética el factor de crecimiento endotelial vascular $^{61}$ que induce angiogénesis ${ }^{62}$ sin éxito, y también incorporar la ATPasa dependiente de calcio del retículo sarcoplás- mico que mejora el manejo del calcio en los cardiomiocitos $^{63}$.

Una nueva estrategia para restaurar el número de las células diana es su conversión directa de otros tipos de células.Dos grupos informaron a principios del 2012 de la conversión in vivo de los fibroblastos cardíacos en miocitos ${ }^{64}$, por introducción de un combinado de genes de los factores adecuados. $\mathrm{Y}$ posteriormente se publica otro conjunto de genes que permiten a los fibroblastos convertirse in vivo en cardiomiocitos más maduros ${ }^{65}$. Queda mucho por mejorar la técnica pero el panorama de la reprogramación in vivo empieza a dilatarse.

Por ultimo, señalamos los avances más recientes dirigidos a conseguir bancos de células pluripotencialescapaces de diferenciarse a cualquiera de los tipos que forman el cuerpo humano, de forma no sean rechazadas inmunológicamente por el paciente. Preparar para cada paciente las células que se necesiten a partir del rejuvenecimiento de las suyas, es largo, laborioso y costoso. Es necesario lograr un sistema de suministro de células pluripotenciales. Recientemente, el gobierno japonés ha aprobado a Yamanaka la creación de líneas celulares a partir de los miles de muestras de sangre del cordón umbilical guardadas ${ }^{66}$. Se pretende de crear, para el 2020, un conjunto estándar de 75 líneas de células iPS que son suficientes como para poder ser toleradas sin rechazo por el $80 \%$ de la población japonesa. La mayoría de los bancos iPSde otros países se especializan en células de enfermos para la investigación.

\section{BIBLIOGRAFÍA}

1. Yamanaka S. A Fresh Look at iPS Cells. Cell 2009; 137: 13-17.

2. Thomson A, IsKovit-Eldor J, Shapiro S. S. Embryonic stem line derived from human blastocysts. Science 1998; 282:1145-1147.

3. TAKAHASHI $\mathrm{K}$, YAMANAKA S. Induction of pluripotent stem cells from mouse embryonic and adult fibroblast cultures by defined factors. Cells 2006; 126: 663-676.

4. Окiтa K, IchisaKa T, Yamanaka S. Generation of germ line-competent induced pluripotent stem cells. Nature 2007; 448: 313-317. 
5. Yu J, Vodyanik MA, Smuga-Otto K, AntosiewiczBourget J, Frane JL, Tian S et al. Induced pluripotent stem cell lines derived from human somatic cells. Science 2007; 318:1917-1920.

6. Hanna J, Wernig M, Markoulaki S, Sun CW, Meissner A, CAssady JP et al. Treatment of sickle cell anemia mouse model with iPS cells generated from autologous skin. Science 2007; 318: 1920-1923.

7. KajI K, Norrby K, Paca A, Mileikovsky, M, МohSENI P, WOLTJEN K. Virus-free induction of pluripotency and subsequent excision of reprogramming factors Nature 2009; 458: 771-775.

8. Nakagana M, Koyanagi M, Tanabe K, Takahashi $\mathrm{K}$, ICHISAKA T, Aor T et al. Generation of induced pluripotent stem cells without Myc from mouse and human fibroblasts. Nature Biotechnology 2008; 26:101-106.

9. PERA MF. Low-risk reprogramming. Nature 2009; 458: 715-716.

10. Fuchs E. The impact of cell culture on stem cell research. Cell Stem Cell 2012; 10: 640641.

11. Park IH, Arora N, Huo H, Maherali N, Ahfeldt T, Shimamura A et al. Disease-specific induced pluripotent stem cells. Cell 2008; 134: 877886.

12. Ebert AD, Yu J, Rose FF, Mattis VB, Lorson CL, Thomson JA. Induced pluripotent stem cells from a spinal muscular atrophypatient. Nature 2009; 457: 51-61.

13. YamanaKa S. Patient-specific pluripotent stem cells become even more accessible. Cell Stem Cell 2010; 7: 1-2.

14. Taura D, Noguchi M, Sone M, Hosoda K, Mori E, OKADA Y et al. Adipogenic differentiation of human induced pluripotent stem cells: Comparison with that of human embryonic stem cells. FEBS Letters 2009; 583: 1029-1033.

15. Zhang J, Wilson G, Soerens A, Koonce C, Yu J, PALECEK $\mathrm{S}$ et al. Functional cardiomyocytes derived from human induced pluripotent stem cells. Circulation Research 2009; 104: E30-E41.

16. Zhou Q, Brown J, Kanarek A, Rajagopal J, MelTON DA. In vivo reprogramming of adult pancreatic exocrine cells to b-cells. Nature 2008; 455: 627-633.

17. Vierbuchen T, Otermeier A, Pang ZP, Kokubo Y, SudHof TC, WeRnig M. Direct conversion of fibroblasts to functional neurons by defined factors. Nature 2010; 463: 1035-1041.

18. Huang P, He Z, Ji S, Sun H, XIANg D, Liu C et al. Induction of functional hepatocyte-like cells from mouse fibroblasts by defined factors. Nature 2011; 475: 386-389.
19. Ieda M, Fu JD, Delgado-Olguin P, Vedantham V, HAYAShi Y, BRUneAu B et al. Direct Reprogramming of fibroblasts into functional cardiomyocytes by defined factors. Cell 2010; 142 : 375-386.

20. Szabo E, Rampalli S, Risueño R, Schnerch A, MitChell R, Fiebig-Comyn A et al. Direct conversion of human fibroblasts to multilineage blood progenitors. Nature 2010; 468: 521-526.

21. Yamanata S, Blau HM. Nuclear reprogramming to a pluripotent state by three approaches. Nature 2010; 465: 704-712.

22. Eggan K, Tackett M, Baldwin K, Osborne J, Gogos J, Chess A et al. Mice cloned from olfactory sensory neurons. Nature 2004, 428: 44-49.

23. TAKAhashi K. Direct reprogramming. Dev Growth \& Differ 2010; 52: 319-333.

24. Zhang XY, Yamanaka S, Kim S, Miura K, Iwao H. NAT1, a homologue of the eukaryotic translation initianion factor $4 \mathrm{G}$, is essential for cell differentiation and mouse development. Jpn J Pharmacol 1999; 79: 163P.

25. Mikkelsen T S, Hanna J, Zhang X, Ku M, Wernig M, Schorderet $P$ et al. Dissecting direct reprogramming througt integrative genomic analysis. Nature 2008; 454: 49-54.

26. Judson R, Babiarz J, Venere M, Blelloch R. Embryonic stem cell-specific microRNAs promote induced pluripotency. Nature Biotechnology 2009; 27:459-461.

27. Gaspar-Maia A, Alajem A, Polesso F, Sridharan R, Mason M, Heidersbach A et al. Chd1 regulates open chromatin andluripotency of embryonic stem cells. Nature 2009; 460: 863-U97.

28. WAng Y, Armstrong S. Cancer: inappropriate expression of stem cell programs? Cell Stem Cell 2008; 2: 297-299.

29. Blelloch R, Venere M, Yen J, Rhamalo-Santos M. Generation of induced pluripotent stem cells in the absence of drug selection. cell stem Cell 2007; 1: 245-247.

30. YAmANAKA S. Elite and stochastic models for induced pluripotent stem cell generation. Nature 2009, 460: 49-50.

31. YamanaKa S. Induced pluripotent stem cells: past, present and future. Cell Stem Cell 2012; 10: 678-684.

32. Maherali N, Hochedlinger K. Guidelines and techniques for the generation of induced pluripotent stem cells. Cell Stem Cell 2008; 3: 595-605.

33. Chin M, Mason M, Xie W, Volinia S, Singer M, PeTERSON $\mathrm{C}$ et al. Induced pluripotent stem sells and embryonic stem cells are distinguished by gene expression signatures. Cell Stem Cell 2009; 5: 111-123. 
34. Doi A, Park IH, Wen B, Murakami P, Aryee M, IRIZARRY $\mathrm{R}$ et al. Differential methylation of tissue and cancerspecific CpG island shores distinguishes human induced pluripotent stem cells, embryonic stem cells and fibroblasts. Nature Genetics 2009; 41: 1350-1353.

35. Guenther M, Frampton G, Soldner F, Hockemeyer D, Mitalipova M, JaEnisch R et al. Chromatin structure and gene expression programs of human embryonic and induced pluripotent stem cells. Cell Stem Cell 2010; 7: 249-257.

36. Itskovitz-Eldor J, Schuldiner M, Karsenti D, EdEN A, Yuhuka O, Амiт M et al. Differentiation of human embryonic stem cell into embryoid bodies comprising the three embryonic germ layers. Mol Med 2000; 6: 88-95.

37. Ghosh Z, Wilson K, Wu Y, Hu S, Quertermous T, Wu J. Persistent donor cell gene expression among human induced pluripotent stem cells contributes to differences with human embryonic stem cells. PLoS ONE 2010; 5: $1-10$.

38. Boulting G, Kiskinis E, Croft G, Amoroso M, OAKLEY D, WAINGER B et al. A functionally characterized test set of human induced pluripotent stem cells. Nat Biotechnol 2011; 29: 279-283.

39. Kiskinis E, EgGan K. Progress toward the clinical application of patient-specific pluripotent stem cells. J Clin Invest 2010; 120: 51-59.

40. Hirami Y, Osakada F, TaKahashi K, OKita K, YamaNAKA S, IKEDA $\mathrm{H}$ et al. Generation of retinal cells from mouse and human induced pluripotent stem cells. Neuroscience Letters 2009; 458 : 126-131.

41. Aiba K, Nederezov T, Piao Y, Nishiyama A, Matoba R, Sharova L et al. Defining developmental potency and cell lineage trajectories by expression profiling of differentiating mouse embryonic stem cells. DNA Research 2009; 16: $73-80$.

42. Gore A, Li Z, Fung HL, Young J, Agarwal S, AnTosiewicz-Bourget J et al. Somatic coding mutations in human induced pluripotent stem cells. Nature 2011; 471: 61-67.

43. Hussein S, Batada N, Vuoristo S, Ching R, Autio $R$, NäRVA E et al. Copy number variation and selection during reprogramming to pluripotency. Nature 2011; 471: 58-62.

44. Zhao T, Zhang ZN, Rong Z, Xu Y. Immunogenicity of induced pluripotent stem cells. Nature 2011; 474: 212-215.

45. Quinlan A, Boland M, Leibowitz M, Shumilina S, Pehrson S, Baldwin K et al. Genome sequencing of mouse induced pluripotent stem cells reveals retroelement stability and infrequent dna rearrangement during reprogramming. Cell Stem Cell 2011; 9: 366-373.

46. Okano H, Nakamura M, Yoshida K, Okada Y, TsujI $\mathrm{O}$ et al. Steps toward safe cell therapy using induced pluripotent stem. Cells Circ Res 2013; 112: 523-533.

47. Politis M, Lindvall O. Clinical application of stem cell therapy in Parkinson's disease. BMC Medicine 2012; 10: 1-7.

48. Takayama N, Nishimura $\mathrm{S}$, Nakamura $\mathrm{S}$, Shimizu T, Ohnishi R, Endo $\mathrm{H}$ et al. Transient activation of c-MYC expression is critical for efficient platelet generation from human induced pluripotent stem cells. J Exp Med 2010; 207: 2817-2830.

49. Nori S, Okada Y, Yasuda A, Tsuji O, TaKahashi Y, KoBAYASHI Y et al. Grafted human-induced pluripotent stem-cell-derived neurospheres promote motor functional recovery after spinal cord injury in mice. Proc Nat Acad Sci 2011; 108: 16825-16830.

50. Окамото S, TAKAнаSнI M. Induction of retinal pigment epithelial cells from monkey iPS cells. Invest Ophth Vis Sci 2011; 52: 87858790.

51. Cyranoski D. Stem cells cruise to clinic. Nature 2013; 494: 413.

52. Kobayashi Y, Okada Y, Itakura G, Inai H, Nishimura S, YASudA A et al. Pre-evaluated safe human ipsc-derived neural stem cells promote functional recovery after spinal cord injury in common marmoset without tumorigenicity. PLoS ONE 2012; 7: e52787.

53. Israel M, Yuan S, Bardy C, Reyna S, Mu Y, HeRRERA $C$ et al. Probing sporadic and familial Alzheimer's disease using induced pluripotent stem cells. Nature 2012; 482: 216-220.

54. Brennand K, Simone A, Jou J, Gelboin-Burkhart C, Tran N, SAngar S et al. Modelling schizophrenia using human induced pluripotent stem cells. Nature 2011; 473: 221-225.

55. Tanaka T, Takahashi K, Yamane M, Tomida S, NAKAMura S, Oshima $\mathrm{K}$, et al. Induced pluripotent stem cells from CINCA syndrome patients as a model for dissecting somatic mosaicism and drug discovery. BLOOD 2012; 120: 1299-1308.

56. Si-Tayeb K, Duclos-Vallée JC, Petit, MA. Hepatocyte-like cells differentiated from human induced pluripotent stem cells (iHLCs) are permissive to hepatitis $\mathrm{C}$ virus (HCV) infection: HCV study gets personal. J Hepat 2012; 57: 689-691.

57. Raya Á, Rodríguez-Piza I, Guenechea G, Vassena R, NAVARro S, Barrero M et al. Disease-corrected haematopoietic progenitors from Fanconi 
anaemia induced pluripotent stem cells. Nature 2009; 460: 53-59.

58. Hayashi Y, Saitou M, YamanaKa S. Germline development from human pluripotent stem cells toward disease modeling of infertility. Fertil Steril 2012; 97: 1250-1259.

59. López-Moratalla N. ¿Resucitan al inicio del 2009 las células troncales procedentes de embriones? Cuadernos de Bioética 2009; 70 : 471-486.

60. Yoshida Y, Yamanaka S. An emerging strategy of gene therapy for cardiac Disease. Circ Res 2012; 111: 1108-1110.

61. Losordo DW, Vale PR, Symes JF, Dunnington $\mathrm{CH}$, Esakof DD, MaYsky M et al. Gene therapy for myocardial angiogenesis: initial clinical results with direct myocardial injection of phVEGF165 as sole therapy for myocardial ischemia. Circulation 1998; 98: 2800-2804.

62. Isner JM, Pieczek A, Schainfeld R, Blair R, Haley L, AsAHARA T, et al. Clinical evidence of angiogenesis after arterial gene transfer of phVE-
GF165 in patient with ischaemic limb. Lancet 1996; 348: 370-374

63. Jessup M, Greenberg B, Mancini D, Cappola T, PaUly DF, JASKI B, Yaroshinky A, Zsebo KM, HAJJAR RJ. Calcium upregulation by percutaneous administration of gene therapy in cardiac disease (CUPID): a phase 2 trial of intracoronary gene therapy of sarcoplasmic reticulum $\mathrm{Ca} 2+-\mathrm{ATPase}$ in patients with advanced heart failure. Circulation 2011; 124 : 304-313.

64. Qian L, Huang Y, Spencer CI, Foley A, Vedantham $\mathrm{V}$, Liu $\mathrm{L}$ et al. In vivo reprogramming of murine cardiac fibroblasts into induced cardiomyocytes. Nature 2012; 485: 593-598.

65. Inagawa K, Miyamoto K, Yamakawa H, Muraoka N, SADAHIRO T, UmeI T et al. Induction of cardiomyocyte-like cells in infarct hearts by gene transfer of Gata4, Mef2c, and Tbx5. Circ Res 2012; 111: 1147-1156.

66. Cyranoski D. Stem-cell pioneer banks on future therapies. Nature 2012; 488: 139. 